\title{
In-game advertising: Consumers' attitude and the effect of product placements on memory
}

\author{
Shu-Hsun Ho ${ }^{1}$, Yu-Ling Lin ${ }^{2 \star}$ and Yu-Ting Yang ${ }^{1}$ \\ ${ }^{1}$ Department of Business Administration, Providence University, Taichung, Taiwan. \\ ${ }^{2}$ Department of Business Administration, National Chin-Yi University of Technology, Taichung, Taiwan.
}

Accepted 26 May, 2011

\begin{abstract}
This study investigated the effectiveness of product placement in video games by testing participants' brand and product memory along with three distinctive types of product presentation: associative placement, illustrative placement and demonstrative placement. Memory measures comprise explicit memory and implicit memory. The results indicated that the associative placement had a lower level of explicit memory (recall and recognition) than illustrative and demonstrative placements, while the implicit memory of associative placement was higher than illustrative and demonstrative placements. Based on these results, companies should use illustrative or demonstrative placements for new products to help consumers remember new brands and use associative placements for existing products to increase consumers' purchase intention.
\end{abstract}

Key words: In-game advertising, consumers' attitude, product placements, explicit memory, implicit memory, video game.

\section{INTRODUCTION}

In recent years, video games have replaced TV and movies to become the major source of young people's entertainment, representing a potentially powerful marketing channel (Chaney et al., 2004; Nelson, 2002; Yang et al., 2006). The global revenues earned from video games reached $\$ 46.4$ billion in 2007 , more than boxoffice revenues for the global movie industry (\$26.7 billion) in the same year (Motion Picture Association of America, 2009; Pidgeon, 2008). Marketers have noticed a significant change in consumers' entertainment-related interests. Advertisers have taken notice of such changes, spawning the in-game advertising era. Thus, marketers, when deciding how to apportion their budgets, take into account new lifestyle patterns and utilize video games as a means of reaching adolescent and young adult markets (Chaney et al., 2004; Nelson et al., 2004).

As more customers try to avoid advertisements, there has been growth in brand placement: the practice of integrating brands into entertainment media, particularly television and film (Thomas and Kohli, 2011). Some can

\footnotetext{
*Corresponding author Email: yllin@nuct.edu.tw.
}

be found in television series or shows, theatre plays, songs, videogames and novels (Kretchmer, 2004; Moser et al., 2004). Certain advertisers have placed their brands or products into video games that ideally fit with their brands or products (Layton, 2007). For example, BMW provides various models of racing car choices in carracing games; an Adidas billboard is displayed in the background of the computer game FIFA International Soccer. Nike, Sony-BMG and Toyota are just a handful of the companies that have built storefronts, billboards, or news tickers in Second Life, a fashionable and prosperous online game. Winkler and Buckner (2006) reported that advertisements in video game work more effectively than other media for products and brands. The advantages of product placement in video games over other media include the capacity to increase involvement due to the reception context (passive versus active), the ability to target specific consumer markets and the longer shelf-life than other media (Hudson and Hudson, 2006; Nelson, 2002).

Advertising interactions can be classified into two receptive contexts: passive interaction and active interaction. Media providing two-way communication are active whereas one-way message delivery is a passive 
interaction medium. Most TV programs and movies are classified as passive-interactive media, which are relatively difficult to receive audiences' immediate responses. On the other hand, video games are activeinteractive medium because players are able to have and are even required to have spontaneous interactions, responses and actions (Lee and Faber, 2007; Yang and Wang, 2008). People by nature are more impressed with and interested in active interaction rather than passive interaction (Acar et al., 2007). Video games have unique characteristics of interactivity among players and sensory immersion (Glass, 2007; Lee and Faber, 2007), which enable games to be more lively and closer to audiences than other media (Molesworth, 2006; Nelson et al., 2004). Compared to traditional advertisements, it is easier and more efficient for marketers to produce and place targeted brands in video games (Chaney et al., 2004; Glass, 2007; Yang and Wang, 2008).

However, media's influence on consumer involvement suggests that new research is needed to examine the effectiveness of product placement in video games (Chaney et al., 2004; Grigorovici and Cornstantin, 2004; Nelson, 2002; Schneider and Cornwell, 2005). The existent literature generally relies on memory measures to assess the effectiveness of product placement (Auty and Lewis, 2004; d'Astous and Chartier, 2000; Gupta and Gould, 2007; Law and Braun, 2000; Nelson, 2002; Russell, 2002). Consistent with the memory literature, the explicit and implicit tests revealed various results regarding to placement effectiveness (Law and Braun, 2004). Duke and Carlson (1993) suggested that consumers' purchasing decisions could be influenced not only by conscious processes (explicit memory), but also by unconscious processes (implicit memory), especially at the time of purchase (Goode, 2007). Conscious processes involve those memories recalled from prior events through intention or awareness; unconscious processes involve those memories that occur when the person is unaware of the process itself.

However, till date, few studies have examined the effectiveness of different types of product placement in various media. Russel (2002) demonstrated that brand attitude can be improved through the congruity between the modality of product placement and plot connection. Lee and Faber (2007) examined the relationship between the product category of the brand placement and the content of the game. If consistency exists between the product and video game, the game will be more vivid and real. Yang et al. (2006) found that in-game advertising demonstrated a higher level of impact on audience's implicit memory than explicit memory. Winkler and Buckner (2006) mentioned that products can be integrated into a gaming environment to various degrees of immersion, ranging from associative to demonstrative. Appropriate methods of integration can be selected to best communicate the brand message, according to the product and scope of the campaign.

The current study adopted the three proposed types of
Product placement associative, illustrative, and demonstrative whose effectiveness has not been investigated yet. Using these types of product placement, the study will consider the consistency between the game and product, which can be determined by the degree of product immersion in the gaming environment. Thus, this study will examine the congruity of the product and game design in different types of product placements and investigate the effectiveness of each type of placement by measuring participants' explicit and implicit memory.

\section{LITERATURE REVIEW}

\section{Product placement}

Product placements (a product and/or a brand intentionally placed in a cultural medium) are mushrooming in movies nowadays (Lehu and Bressoud, 2008). Product placement has been defined as the placed inclusion of branded products or brand signs through visual, verbal and audio-visual means within mass media (Karrh, 1998; Lee and Faber, 2007; Nelson et al., 2004). Russell (2002) described product placement with a three-dimensional framework: screen placement (visual component), script placement (audio component) and plot placement (connection to the plot). Early researchers studied the effectiveness of various types of product placement, mainly in films (Auty and Lewis, 2004; d'Astous and Chartier, 2000; Gould et al., 2000; Mckechnie and Thou, 2003) and television (La Ferle and Edwards, 2006; Reijmersdal et al., 2007; Roehm et al., 2004; Tiwsakul et al., 2005). Gupta and Lord (1998) examined the impact of product placement on consumer recall in terms of different types of product placement (for example, prominence versus subtlety and audio versus visual). The results revealed that prominent placement of products can induce a higher level of consumer recall than subtle placement. Furthermore, participants could better recall products in audio placement than those in visual placement. Thus, prominent placement, high plot connection, and visual-auditory sensorial cues can lead to greater recall.

Product placement in video games first emerged in the 1980s, when Sega placed banners advertising Marlboro in its auto-racing arcade games (Glass, 2007; Grigorovici and Constantin, 2004). Since then, academic research regarding the effect of product placement in video games has increased (Glass, 2007). Nelson (2002) examined game players' level of instant recall and delayed recall. In racing games, approximately $30 \%$ of placements were recalled immediately after the game; however, when participants were retested five months later, this number significantly decreased to only $10 \%$. Nelson further concluded that local brands were much easier to be recalled than national brands.

Winkler and Buckner (2006) identified three types of 
product placement: associative, illustrativ and demonstrative. Associative placement occurs when the brand or product is placed in the background. For example, the sports game Jack Daniel allows advertisers the choice of imprinting logos on or around a pool table, which not only provides a natural setting for the advertisements, but also appeals to the targeted demographic. Illustrative placement occurs when the brand or product placed in the game is prominently featured (for example, General Mills' "Cinnamon Toast Crunch" launched a series of games hosted through different settings).

Demonstrative placement involves the highest integration, boosting messaging effectiveness by presenting the product in its natural context and inviting the consumer to interact with it (for example, the avatars in the FIFA international soccer wear Adidas to promote the function of the shoes).

Among other studies, these three categories are well fitted into the various types of product placement in video games. Hence, the current study will further evaluate the effectiveness of product placement in video games in terms of these three types, respectively.

\section{Memory}

Players' awareness of product and brand is the essential goal of in-game advertising (Winkler and Buckner, 2006). Nelson (2002) proposed that increasing brand awareness is one of the goals of product placement and that memory-based measures (recognition or recall) are suitable for testing the effectiveness of such placement. Much of the more recent empirical research related to product placement has focused on the effectiveness in video games (Karrh, 1998; Yang et al., 2006) rather than in conventional media such as TV and films. Memory measures pervade advertising research and play as an important means of investigative issues such as communications usefulness and product valuation.

Recently, quite a few scholars suggested that memory should be further divided into explicit memory and implicit memory (Auty and Lewis, 2004; Shapiro and Krishnan, 2001).

Explicit memory and implicit memory work within varied neural structures; explicit memory is characterized as conscious collection while implicit memory is unconscious recollection (Percy, 2006). If the marketer's goal for placement is to increase brand awareness and demonstrate brand benefits, explicit measures might be suitable measures of effectiveness.

However, for consumers' buying decisions, implicit measures have been demonstrated to be a better tool for implicit memory, which is closer to the consumer's actual behavior than explicit memory (Law and Braun, 2004). Thus, the current research investigates the effectiveness of product placement using two types of measures: explicit memory and implicit memory.

\section{Explicit memory}

Explicit memory is elicited from an exposure event in other words, an intentional effort to access and retrieve information from a previous stimulus experience. Such memory is characterized by a person's conscious recollection of the event and reflects what the person remembers about the event (Lee, 2002). Explicit memory can be measured in three ways, free recall, cued recall and recognition which instruct the individual to remember information from the experience (Duke and Carlson, 1993). In a way, memory is measured by asking participants to recollect or recognize information from prior exposure.

The two primary measures of explicit memory are recall and recognition, which measure explicit memory from different aspects (Yang et al., 2006). Recall, which varies from free recall to high cued recall, is defined as the rebuilding of a stimulus from a previous exposure (Duke and Carlson, 1993). Managers are more likely to use recall measures because they can understand by instinct and rapidly defend recall scores. However, recall scores are sometimes unrelated to attitude structures and often fail to correlate with persuasion, purchasing behavior, or actual product choice (Law and Braun, 2004).

Another type of explicit memory is recognition. Recognition is similar in nature to recall, but constructs better and more consistent results (Law and Braun, 2004). Recognition is measured by directly testing participants on episodes from prior exposure. Furthermore, both managers and researchers have used recognition in an effort to address the limitations of recall. Recognition is similar in nature to recall, but produces better and more reliable results (Law and Braun, 2004). Recognition is measured by directly testing participants on episodes from prior exposure (Acar et al., 2007). For example, participants are asked to judge whether they remember seeing a brand in the media.

In regards to product placement, most studies have used explicit memory measures to test effectiveness (Auty and Lewis, 2004; Nelson, 2002). For example, Gupta and Lord (1998) found that prominently placed products are better remembered than those unnoticeable placements appearing in the background. Moreover, Russell (2002) reported that verbal placements were better recalled than visual placements. The congruence of the brand and the plot seemed to improve recognition for visual placements.

However, Law and Braun (2000) claimed that little direct relationship exists between advertising recall and consumer behavior. Event exposure not only influences conscious memory process (explicit memory), but also impacts the non-conscious memory process (implicit memory) (Goode, 2007; Law and Braun, 2000; Yang et al., 2006). Indeed, in the real world, consumers are constantly bombarded with advertising messages; an extensive time lapse often occurs between advertising exposure and purchase opportunity. These two factors 
are likely to lead to a reduction in explicit memory, thereby stressing the importance of understanding the influence implicit advertising memory has on consumer behavior (Goode, 2007). Implicit memory may influence sales through its relatively important effect on the product placement even if the details of the original exposure are not remembered (Yang et al., 2006).

\section{Implicit memory}

Unlike explicit memory, which is influenced by the individual's previous exposure to information, implicit memory is revealed when previous experiences assist performance in a task that does not require conscious or intentional recollection of those experiences (Duke and Carlson, 1993). Implicit memory is believed to exist if task performance (for example, word fragment completion or choice) is facilitated or influenced by recently presented information (Schacter, 1987). Lee (2002) found that incidental exposure to advertising had no influence on explicit memory, yet it did influence subsequent brand choice. The effect of explicit memory is indistinct as implicit memory is closer to the consumer behavioral and serves as a form of memory used in everyday situations. Furthermore, an individual's explicit memory declines over time, whereas implicit memory tends to last longer after the initial exposure to the stimuli (Shapiro and Krishnan, 2001; Yang et al., 2006). Therefore, the implicit memory has been proposed as an important concept in advertising research.

Extant literature has suggested that people are more likely to use information to which they have been recently exposed when performing a subsequent task, even though they may not be consciously attempting to retrieve information from the exposure (Lee, 2002). Law and Braun (2000) found that participants were more likely to purchase items for a friend's new apartment when the items had appeared in an episode of TV program participants had just watched than the control item, which did not show in the episode. Participants not only show a higher level of cognition of the brand (that is, the effect of explicit memory), but also indicate such cognition influences their purchasing decisions (that is, the effect of implicit memory). Similarly, Yang et al. (2006) indicated that college students had low levels of explicit memory for the brand, while demonstrating high levels of implicit memory for the brand placed in video games. Auty and Lewis (2004) also pointed to the fact that implicit memory seems to be more important than explicit recall.

Measuring implicit memory is an important aspect of effective product placement (Duke and Carlson, 1993; Yang et al., 2006). Measures of implicit memory can identify advertising effects resulting from incidental advertising exposure that occurs when people are not fully attending to the advertisement (Shapiro and Krishnan, 2001). Thus, the limitations of explicit memory measures in evaluating advertising performance have led researchers to consider implicit memory as a supplementary method for measuring advertising effects.

\section{Attitude toward product placement}

Several researchers concur that product placement can enhance the reality of the advertising plots (Balasubramanian et al., 2006; Gupta and Gould, 1997; Gould et al., 2000). d'Astous and Séguin (1999) demonstrated that three different situations influence attitudes toward product placement: 1 . When products appear with celebrity endorsement (d'Astous and Chartier, 2000; Yang et al., 2006). 2. When product placement is congruent with a scene presented. 3 . When products are prominently displayed (Auty and Lewis 2004). Russell (2002) further identified a possible factor for successful placement as plot integration. Well-integrated placements appear to be more persuasive in changing attitudes than prominent but incongruent placements. In addition, Russell and Stern (2006) pointed out that the story characters' attitudes toward the placed products will influence individuals' attitudes toward the same products. Generally speaking, extensive research of product placement in movies or TV indicates a positive effect. Product placement is by far more accepted by consumers in comparison to other traditional advertising messages (Nebenzahl and Secunda, 1993). Furthermore, most players welcome in-game advertising because it makes the game more authentic and dramatic. Compared to product placement in traditional media, customers are more willing to accept it in games.

Till date, attitudes toward product placement in media other than movies and televisions have received little attention despite increased product placement in games. Nelson (2002) first examined players' attitudes toward product placement in video games, determining that consumers were generally positive toward placements in video games as they feel the reality when they see familiar brands in games. In addition, Nelson et al. (2004) demonstrated a positive relationship between attitudes toward advertising in general and attitudes toward product placements. Attitudes were positively related to consumers' purchasing behaviors. Moreover, players' attitudes toward placements vary according to the way in which they are presented. For example, Grigorovici and Constantin (2004) concluded that the 3D content better enhances consumers' attitudes toward the brand than 2D content. Thus, in general, players accept product placement in video games with ease because they consider such placements to make games more vivacious and competitive.

\section{HYPOTHESES}

Gupta and Lord (1998) found that prominent placements have a stronger effect on consumers' explicit memory 
rather than subtle placements. Winkler and Buckner (2006) classified the various types of product placements according to the level of integration into three categories: associative, illustrative and demonstrative. Associative placement, in which the brand or product is set in the background, is close to "subtle" product placement, where the placements are not directly referenced or strikingly noticeable. Meanwhile, the illustrative placement, as a "prominent" product placement, uses obvious features to place the brand or product in video games; the product itself plays a significant role in game play. Finally, demonstrative placement (the highest level of brand incorporation) allows players to experience the product in its natural context as it is reproduced in the gaming environment (Winkler and Buckner, 2006). Thus, demonstrative placement is the most prominent placement among these three types.

According to the level of prominence, the three types of product placement namely, free recall, cued recall and recognition are ranked from high to low as demonstrative, illustrative and associative. Applying the research of Gupta and Lord (1998) and placement types mentioned by Winkler and Buckner (2006), the current study presumes that the effectiveness of each placement on explicit memory is expected to rank from high to low as demonstrative, illustrative and associative. Based on the discussion thus far, the following hypotheses have been developed:

$\mathrm{H}_{1}$ : The effectiveness of product placement influencing participants' explicit memory, ranked highest to lowest, is demonstrative placement, illustrative placement and associative placement.

$\mathrm{H}_{1 \mathrm{a}}$ : The effectiveness of product placement influencing participants' recall, ranked highest to lowest, is demonstrative placement, illustrative placement and associative placement.

$\mathrm{H}_{1 \mathrm{~b}}$ : The effectiveness of product placement influencing participants' recognition, ranked highest to lowest, is demonstrative placement, illustrative placement and associative placement.

Law and Braun (2000) demonstrated that, although people could not clearly remember brands appearing in a television show (in terms of the effect of explicit memory), they presented preferences toward these brands and showed a higher willingness to purchase those placed products (in terms of the effect of implicit memory). Thus, compared to prominent placement, more subtle placements have a greater influence on consumers' implicit memory, even though they were least recalled (Law and Braun, 2004). Implicit measures are more appropriate for predicting consumers' behaviors because they come closer to consumers' actual behavior (for example, brand choice and preference). Associative placements are considered to be the most subtle among the three placements (Winkler and Buckner, 2006), given that subtle placements more effectively impact implicit memory than prominent placements. Therefore, the following hypothesis is proposed:

$\mathrm{H}_{2}$ : The effectiveness of product placement influencing participants' implicit memory, ranked highest to lowest, is associative placement, illustrative placement and demonstrative placement.

Consumers' attitudes will determine their preferences for brands and purchasing intentions. It is important that advertisers know players' attitudes toward in-game advertising. Indeed, Gupta and Gould (1997) found that, when participants watch more films, they exhibit a higher level of positive attitude toward product placement. Similarly, Molesworth (2006) claimed that most players react positively to product placement in games because they regard in-game advertising as beneficial to players, who experience authentic atmospheres while, with advertising profits, game developers are able to design more challenging games. Nelson (2002) also proclaimed that players favored product placements in games, thinking that the practice added to the realism of the game:

$\mathrm{H}_{3}$ : Players have positive attitudes toward product placement in video games.

\section{EXPERIMENTAL INVESTIGATION}

\section{Participants}

A total of 150 participants were randomly assigned to one of three game situations (associative placement, illustrative placement, and demonstrative placement) or to the control group (no product placement). A total of 42 participants played a game that involved an associative-approach placement, 36 played a game with an illustrative-approach, 38 played a game with a demonstrative-approach and 34 were assigned to the control group. Product placement was a between-subjects factor, while memory measure was withinsubject factor. The control group did not complete the recall and recognition test (explicit memory) as participants did not receive product placement treatment. However, the control group completed the implicit memory test as participants were not required to have been exposed to the brands for the test. No participant had any previous experience with the games used in this experiment.

\section{Instruments}

The games were played on a desktop computer with a 19" screen. Although the games were not played in participants' home environments, the testing setting was free and comfortable, without any competing stimuli. All placements were visual in the games; no verbal mentions of any products were included. To avoid the possibility of participants being influenced by the effectiveness of the brand, participants were asked to play two different games within their assigned placement category.

As shown in Figure 1, for example, two games were included in the associative placement category. The first game was table tennis that included the OREO brand on the wall. The object brand was incorporated into the background, without interrupting or influencing the game playing. The second game was a puzzle game that included an unobtrusive Pepsi logo in the background. Meanwhile, 

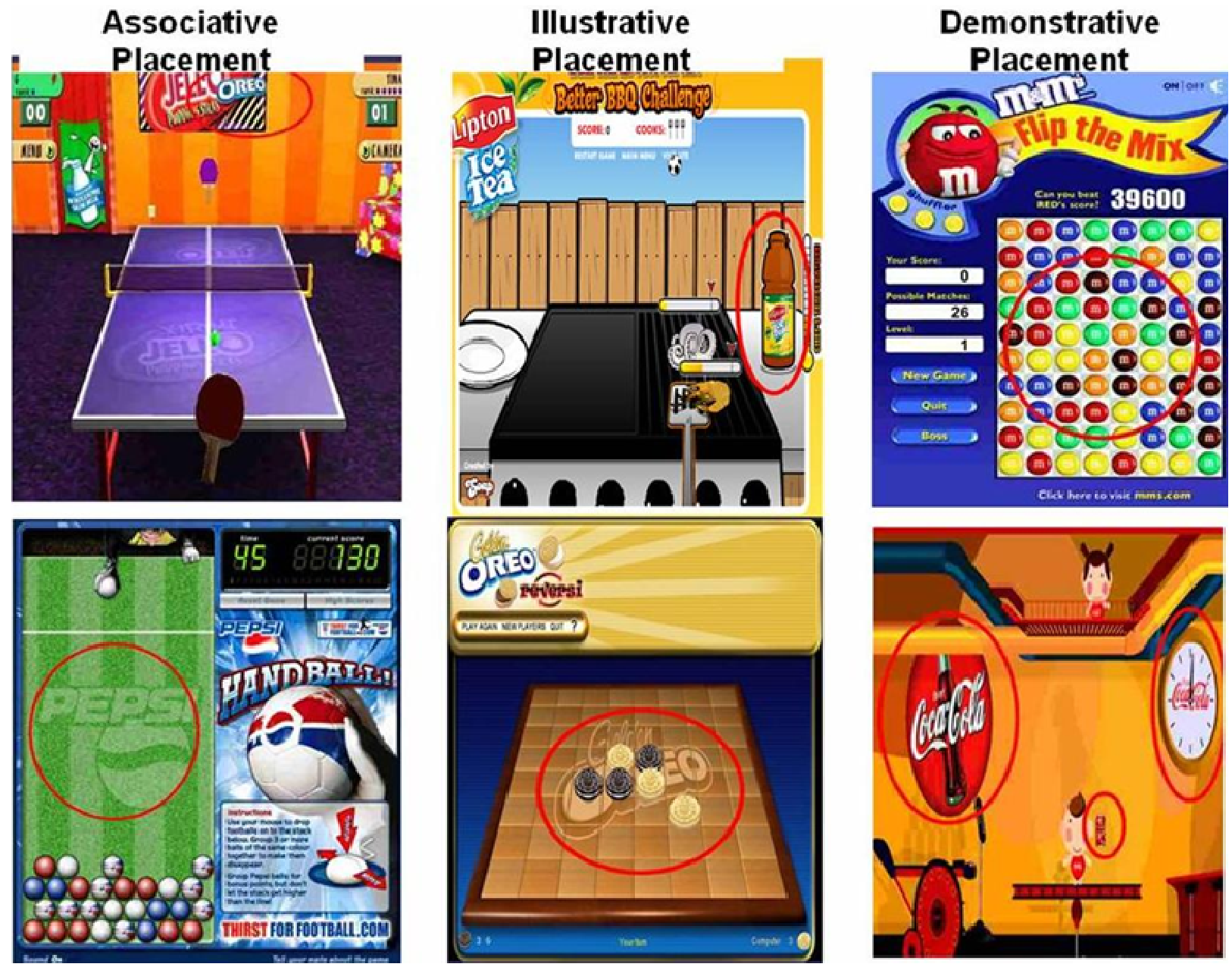

Figure 1. The games with three categories placement.

in the illustrative placement category, two games with different brands (OREO and Lipton) are all shown ostensibly in the games but not interacting with the players. The third category is demonstrative placement; two games not only show brands (that is, Coca Cola and M\&Ms) obtrusively, but also required players to play with the brand-shown subjects for winning the game points.

\section{Procedure and design}

To prevent participants from being influenced by the objective of the experiment, the real purpose of the study was not disclosed. Rather, participants were made to believe that they should focus on the game and provide their opinions and suggestions of the game. The survey was set up in such a way that participants played an advergame first and then filled out the questionnaire.

Each participant took about 25 min to play the games, which included $5 \mathrm{~min}$ of reading the game rules. When ordered to quit the game, participants were administered the memory measure related to the brand placement and attitude toward product placement of the game, which utilized a seven-point Likert scale $(1=$ strongly disagree, 7 = strongly agree) for ranking items. Participants were also asked to list their habits and experiences in playing games, including frequency, time duration, and type of favorite or oftenvisited games. After completing the questionnaire, each participant was thanked with a NT\$50 gift coupon for their participation. In total, 150 unique surveys were collected over a one-month period.

\section{Measurement}

The brand awareness of the products in games was high, scoring at least 6.3 out of 7 on the pre-test, which excluded the bias of brand memory. The survey items were developed based on the findings from related literature (Appendix 1). Questionnaires comprised three sections.

\section{Explicit memory test}

The explicit memory test included open-ended questions to measure recall and recognition tasks. Each game included only one brand (or product). After participants played the game, they were asked to recall and/or recognize the brand that appeared in the game. An intermission was included between the two games. The control group did not complete the recall and recognition tasks because they did not play the games.

\section{Implicit memory test}

Implicit memory was measured using a multiple-choice test. After 
Table 1. Mean proportion of recall, recognition and choice for product placement.

\begin{tabular}{|c|c|c|c|c|c|c|c|c|c|c|}
\hline \multirow{2}{*}{ Factor } & \multicolumn{2}{|c|}{ Ass. } & \multicolumn{2}{|c|}{ III. } & \multicolumn{2}{|c|}{ Demo. } & \multicolumn{2}{|c|}{ Control } & \multirow{2}{*}{\multicolumn{2}{|c|}{ Scheffé testa }} \\
\hline & M & SD & M & SD & $\mathbf{M}$ & SD & M & SD & & \\
\hline Recall & 0.50 & 0.503 & 0.74 & 0.436 & 0.83 & 0.379 & n.a. & n.a. & $12.022^{* * *}$ & Demo. > III. > Ass. \\
\hline Recognition & 0.61 & 0.488 & 0.68 & 0.468 & 0.75 & 0.434 & n.a. & n.a. & $3.461^{* *}$ & Demo. > III. > Ass. \\
\hline Choice & 0.65 & 0.478 & 0.53 & 0.503 & 0.58 & 0.496 & 0.37 & 0.486 & $4.537^{\star \star \star}$ & Ass. > III., Demo. III., Demo. > Control \\
\hline
\end{tabular}

Ass.: associative placement, III.: illustrative placement, Demo.: demonstrative placement, Control: control group, n.a.: not available, a: ">" means "significantly larger " $\mathrm{p}^{*}<0.05, \mathrm{p}^{* *}<0.01, \mathrm{p}^{* * *}<0.001$.

filling out the demographic data, participants handed in their surveys, expecting to leave the experiment. However, another questionnaire awaited them in which they were asked to name two cookies and one drink that they are willing to buy from a shopping list containing ten cookies and four drinks. Although the second survey made no mention of prior games, the brands shown in the games were listed in the consideration set. The open-ended questions of explicit and implicit memory are listed in Appendix 1.

\section{Attitude toward product placement}

Reliability was calculated using SPSS 15.0 on the entire six-item product placement instrument (Appendix 1). It was measured according to respondents' agreement or disagreement on the seven-point Likert scale; the six-item internal reliability resulted in a Cronbach's $\alpha$ of 0.779 . The last section "attitude toward product placement in video game" had a Cronbach's $\alpha$ of 0.777 . All of the Cronbach's $\alpha$ in the survey fell within the minimum acceptable limits (0.7) as identified (Churchill, 1979).

\section{RESULTS}

\section{Sample structure}

A total of 150 university students participated, including 92 males (61.3\%) and 58 females (38.7\%). Most participants were young, between 22 and $25(58.0 \%)$ years old. Participants spent an average 1 to $3 \mathrm{~h}$ a day (54.7\%) playing games. The three most popular types of games were role playing games $(21.7 \%)$, music games $(15.3 \%)$ and puzzle games (12.3\%). Respondents primarily play games on computers $(80 \%)$ rather than consoles. All participants had at least a basic understanding of computers and a basic level of playing computer games.

\section{Hypotheses testing}

$\mathrm{H}_{1}$ predicted that participants' explicit memory would be influenced by different types of product placements. To examine the explicit memory performance on products in the game, each participant's remembrance ratio (number of questions correctly answered to the total number questioned) was analyzed using a one-way ANOVA with three treatments (associative placement, illustrative placement and demonstrative placement).

In the current study, explicit memory was measured using recall and recognition tasks. For the recall measure, the ANOVA analysis highlighted significant differences among the three groups in all factors; the proportion of the target brand names correctly completed was significantly higher for those participants who played the demonstrative game $(\mathrm{M}=0.83, \mathrm{SD}=0.379, \mathrm{~F}(2$, $229)=12.022, p<0.001)$ than the illustrative placement $(\mathrm{M}=0.74, \mathrm{SD}=0.436)$ or associative placement $(\mathrm{M}=$ $0.50, \mathrm{SD}=0.503$ ). Moreover, the Scheffé multiple comparison tests revealed significant differences in each factor among the three groups. Thus, $\mathrm{H}_{1 \mathrm{a}}$ was supported. The results of this memory measure for these games are presented in Table 1.

Furthermore, the recognition measure was also found to have significantly better effects on participants who played the demonstrative game $(\mathrm{M}=0.75, \mathrm{SD}=0.434, F$ $(2,461)=3.461, p<0.05)$ than the illustrative placement $(\mathrm{M}=0.68, \mathrm{SD}=0.468)$ or associative placement $(\mathrm{M}=$ $0.61, S D=0.488)$. As such, $H_{1 b}$ was supported.

$\mathrm{H}_{2}$ stated that product placement effectively influences participants' implicit memory. As predicted, the ratio of the number of target brand(s) shown in the shopping list to the number listed in the consideration set was higher for those participants who played the associative game $(\mathrm{M}=0.65, \mathrm{SD}=0.478, F(3,296)=4.537, p<0.05)$ than the illustrative placement $(\mathrm{M}=0.53, \mathrm{SD}=0.503)$ or demonstrative placement $(M=0.58, S D=0.496)$ as well as the control group $(M=0.37, S D=0.486)$. The results of associative (subtle) placement demonstrated a significantly better influence on consumers' purchase intention than illustrative and demonstrative (prominent) placement $t(84)=2.579, p<0.05)$. However, no significant difference was evident between the illustrative placement and demonstrative placement. Therefore, $\mathrm{H}_{2}$ was partially supported. Participants taking the treatment all showed a higher chance to choose the target brand on their shopping list, compared with the control group, which viewed no product placement. These results proved the effectiveness of product placement. Furthermore, according to the seven-point Likert scale, players demonstrated a significantly positive attitude toward product placement $(\mathrm{M}=6.03, t(149)=86.075, p<0.000)$. Thus, $\mathrm{H}_{3}$ was supported.

\section{DISCUSSION}

Advertisers have used product placement in various 
Table 2. Summary of results.

\begin{tabular}{lll}
\hline Hypothesls & Result \\
\hline $\mathrm{H}_{1} \quad \begin{array}{l}\text { The effectiveness of product placement influencing participants' explicit memory, ranked highest } \\
\text { to lowest, is demonstrative placement, illustrative placement and associative placement. }\end{array}$ & Supported \\
$\mathrm{H}_{1 \mathrm{a}} \quad \begin{array}{l}\text { The effectiveness of product placement influencing participants' recall, ranked highest to lowest, } \\
\text { is demonstrative placement, illustrative placement and associative placement. }\end{array}$ & Supported \\
$\mathrm{H}_{1 \mathrm{~b}} \quad \begin{array}{l}\text { The effectiveness of product placement influencing participants' recognition, ranked highest to } \\
\text { lowest, is demonstrative placement, illustrative placement and associative placement. }\end{array}$ \\
$\mathrm{H}_{2} \quad \begin{array}{l}\text { The effectiveness of product placement influencing participants' implicit memory, ranked highest } \\
\text { to lowest, is associative placement, illustrative placement and demonstrative placement. }\end{array}$ \\
$\mathrm{H}_{3} \quad$ Players have positive attitudes toward product placement in video games.
\end{tabular}

media most recently, video games, which has become a major entertainment activity for the new generation. Games benefit companies advertising their products and brands as well as game developers. The current study investigated the influence of product placement in video games on brand awareness and consumers' purchasing decisions. The results demonstrated that product placement in video games effectively and positively influence players' explicit and implicit memory.

Demonstrative placement is categorized as a prominent placement, showing a significant effect on consumers' explicit memory but less impact on implicit memory. Explicit memory represents the ease by which consumers recognize or remember the brand, whereas implicit memory imperceptibly influences consumers' purchasing decisions. Associative placement, as a more subtle placement, demonstrated better results in influencing consumers' purchasing intentions and, therefore, better persuasion effects.

The level of prominence of the three types of placements, from high to low, are demonstrative, illustrative and associative; however, the level of subtlety, from high to low, is associative, illustrative and demonstrative. Prominent placement has a better effect on consumers' explicit memory, whereas subtle placement has a better effect on consumers' implicit memory. Explicit memory contributes to the brand awareness while implicit memory influences consumers' purchase decision. Given these rules, practitioners are able to develop their own strategy for different purposes and goals.

The extensive and long-term practice of product placement has resulted in consumers becoming bored and tired, even developing a negative attitude toward product placement. They feel as if they have been manipulated and controlled by such a practice. However, as a new media, video games using product placement benefit players. Players attribute product placement as a factor enhancing the realism of the game. Younger generations spend more time playing video games than any other media. Given such a high involvement in video games and beneficial attitudes toward product placement, the younger generation is the target audience of product placement in video games. Academics are encouraged to study the impact and prospects of product placement in video games, while practitioners should immediately take advantage of this new avenue to reach consumers' mind.

The current study investigated the effect of product placement and further classified the placements into three categories. The results stated herein can help advertisers and companies develop more effective planning. If companies look for fame or brand awareness, prominent placement (such as illustrative or demonstrative placement) is a good choice. On the other hand, if companies look for profit, subtle placement (for example, associative placement) is a better choice.

\section{Conclusions}

The results indicated that the associative placement had a lower level of explicit memory (recall and recognition) than illustrative and demonstrative placements, while the implicit memory of associative placement was higher than illustrative and demonstrative placements. As shown in Table 2, both $\mathrm{H}_{1}$ and $\mathrm{H}_{3}$ were supported. $\mathrm{H}_{1}$ predicted that participants' explicit memory would be influenced by different types of product placements. The study find that the effectiveness of product placement influencing participants' explicit memory, both of recall and recognition measure, participants who played the demonstrative game than the illustrative placement or associative placement. Meanwhile, players demonstrated a significantly positive attitude toward product placement in video games. Regardless that $\mathrm{H}_{2}$ stated that product placement effectively influences participants' implicit memory, the results of associative placement demonstrated a 
significantly better influence on consumers' purchase intention than illustrative and demonstrative placement. However, no significant difference was evident between the illustrative placement and demonstrative placement. Therefore, $\mathrm{H}_{2}$ was partially supported.

Based on these results, companies should use illustrative or demonstrative placements for new products to help consumers remember new brands and use associative placements for existing products to increase consumers' purchase intention.

\section{MANAGERIAL SUGGESTIONS}

Advances in technology have made it increasingly easier and more possible for consumers to avoid advertising messages. In today's competitive markets, it is highly likely that many products may not even have access to consumers' consideration sets. Consideration sets are influenced by memory and perceptual processes used in the purchasing decision. The results of the current study concur with Nelson (2002) findings namely, product placement has a strong effect on brand memory.

Prominent placement with clear and ostensive brand placing in the game can help players recognize and memorize the brand even after they stop playing the games. Demonstrative and illustrative placements are appropriate advertising strategies for new product announcements and promotion as building brand awareness is essential at this stage. On the other hand, subtle placement involves placing the brand in an unobtrusive way; it is considered to be somewhat cheaper for advertisers. Existing companies are encouraged to utilize subtle placement like associative placement to influence consumers' decisions regarding advertised products in an effective manner. If the placement strategy is inappropriately applied, it might promote awareness in vain and profit in pain.

In particular, Winkler and Buckner (2006) found that participants did not favor product placement in regards to ethical products. They found that product categories such as alcohol, cigarettes and guns are judged as being less acceptable for product placement than other products. Because of consumers' negative attitudes toward such placement; it will not be appropriate to promote ethical products in games (for example, the various weapons used in sniper or gun fighter scenarios).

\section{Further research}

The popularity of online games seems to have increased the demand for game portals; for example, in 2007 Sony's station reported more than 13 million registered users. This huge online demand, combined with new tracking technologies, has heightened advertisers' interest in advergaming, which offers a targeted, measurable, adjustable form of advertising. Future study may expand the instrument to popular consoles (for example, PS2, Wii and XBOX) or types of game (for example, MMORPG, online games).

In terms of brand or product awareness, it would be fundamentally important to analyze and compare the fundamentally important to analyze and compare the persuasion effect and memory effect of product placement in video games as well as analyze consumers' demographic profiles. Moreover, previous researchers have noted the benefits of placement for enhancing realism (Nelson, 2002). It appears that players more easily remember products to which they have previously been exposed. Thus, researchers should examine favorable factors according to players, such as humor or entertainment elements, and investigate their effects on consumers' explicit and implicit memory. Product placement in video games offers new insights and tools for marketers while providing new topics and subjects for research.

\section{REFERENCES}

Acar A, Robin C, Wang A (2007). Testing the Effects of Incidental Advertising Exposure in Online Gaming Environments. J. Interact. Advert., 8(1): 1-36.

Auty S, Lewis C (2004). Exploring Children's Choice: The Reminder Effect of Product Placement. Psychol. Mark., 21(9): 697-713.

Balasubramanian SK, James A, Karrh PM (2006). Audience Response to Product Placements. J. Advert., 35(3): 115-141.

Bruner GCII (1998). Standardization \& Justification: Do Ad Scales Measure Up? J. Curr. Issues Res. Advert., 20(1): 1-18.

Chaney IM, Lin KH, Chaney J (2004). The Effect of Billboards within the Gaming Environment. J. Interact. Advert., 4 (1): 54-69.

Churchill GA (1979). A Paradigm for Developing Better Measures of Marketing Constructs. J. Mark. Res., 16 (1): 64-73.

d'Astous A, Chartier F (2000). A Study of Factors Affecting Consumer Evaluations and Memory of Product Placements in Movies. J. Curr. Issues Res. Advert., 22(2): 31-40.

d'Astous, Alain, Seguin N (1999). Consumer Reactions to Product Placement Strategies in Television Sponsorship. Eur. J. Mark., 33 (9/10): 896-910.

Duke CR, Carlson L (1993). A Conceptual Approach to Alternative Memory Measures for Advertising Effectiveness. J. Curr. Issues Res. Advert., 15(2): 1-14.

Glass Z (2007). The Effectiveness of Product Placement in Video Games. J. Interact. Advert., 8(1): 1-27.

Goode A (2007). The Implicit and Explicit Role of Ad Memory in Ad persuasion: Rethinking the Hidden Persuaders. Int. J. Mark. Res., 49(1): 95-116.

Gould SJ, Pola BG, Grabner-Kräuter S (2000). Product Placement in Movies: A Cross-Cultural Analysis of Austrian, French and American Consumers' Attitudes toward This Emerging International Promotional Medium. J. Advert., 26(4): 41-58.

Grigorovici DM, Constantin CD (2004). Experiencing Interactive Advertising beyond Rich Media: Impacts of Ad Type and Presence on Brand Effectiveness in 3D Gaming Immersive Virtual Environments. J. Interact. Advert., 4(3): 3-16.

Gupta PB, Lord KR (1998). Product Placement in Movies: the Effect of Prominence and Mode on Audience Recall. J. Curr. Issues Res. Advert., 20(1): 47-59.

Gupta PB, Gould SJ (1997). Consumers' Perceptions of the Ethics and Acceptability of Product Placement in Movies: Product Category and Individual Differences. J. Curr. Issues Res. Advert., 19(1): 37-50.

Gupta PB, Gould SJ (2007). Recall of Products Placed as Prizes Versus Commercials in Game Show. J. Curr. Issues Res. Advert., 29(1): 4353. 
Hudson S, Hudson D (2006). Branded Entertainment: A New Advertising Technique or Product Placement in Disguise? J. Market. Manage., 22(5/6): 489-504.

Karrh JA (1998). Brand Placement: A Review. J. Current Issues Res. Advertis., 20 (2): 31-49.

Kretchmer SB (2004). Advertainment: The Evolution of Product Placement as a Mass Media Marketing Strategy. J. Promot. Manage., 10(1/2): 37-54.

La Ferle C, Edwards SM (2006). Product Placement: How Brands Appear on Television. J. Advert., 35(4): 65-86.

Law S, Braun KA (2000). I'll Have What She's Having: Gauging the Impact of Product Placements on Viewers. Psychol. Mark., 17(12): 1059-1076.

Law S, Braun KA (2004). Product Placement: How to Measure Their Impact. in The Psychology of Entertainment Media Blurring the Lines Between Entertainment and Persuasion, L. J. Shrum, ed., Mahwah, NJ: Lawrence Erlbaum, pp. 63-78.

Layton J (2007). Can I make my living in second life? available at http://electronics.howstuffworks.com/second-life-job.htm.

Lee AY (2002). Effects of Implicit Memory on Memory-based versus Stimulus-based Brand Choice. J. Mark. Res., 39(4): 440-454.

Lee M, Faber RJ (2007). Effect of Product Placement in On-line Games on Brand Memory. J. Advert., 36(4): 75-90.

Lehu, JM, Bressoud E (2008). Effectiveness of Brand Placement: New Insights about Viewers. J. Bus. Res., 61: 1083-1090.

Mckechnie SA, Thou J (2003). Product Placement in Movies: A Comparison of Chinese and American Consumers' Attitude. Int. J. Advert., 22(3): 349-374.

Molesworth M (2006). Real Brands in Imaginary Worlds: Investigating Players' Experiences of Brand Placement in Digital Games. J. Consum. Behav., 5(4): 355-366.

Moser HR, Layne B, Katie S (2004). Product Placement as a Marketing Tool in Film and Television. Natl. Soc. Sci. J., 22(1): 76-86.

Motion Picture Association of America (2009). 2007 Theatrical Market Statistics Report, available athttp://www.mpaa.org/researchStatistics.asp.

Nebenzahl ID, Secunda E (1993). Consumers' Attitudes toward Product Placement in Movies. Int. J. Advert., 12(1): 1-12.

Nelson MR (2002). Recall of Brand Placements in Computer/Video Games. J. Advertis. Res., 42(2): 80-92.

Nelson MR, Keum H, Yaros RA (2004). Advertainment or Adcreep Game Players' Attitudes toward Advertising and Product Placements in Computer Games. J. Interact. Advert., 4(3): 3-30.

Norris CE, Colman AM (1993). Context Effects on Memory for Television Advertisements. Soc. Behav. Pers., 21(4): 279-296.

Percy L (2006). Are Product Placement Effective? Int. J. Advert., 25(1): $112-114$.
Pidgeon B (2008). Worldwide Videogame Console Hardware and Software 2008-2012 Forecast and Analysis: Bigger Market, Bigger Challenges. Retrieved February 20, 2009, from the World Wide Web: http://www.idc.com/getdoc.jsp?containerld=211264.

Reijmersdal EA, Neijens PC, Smit EG (2007). Effects of Television Brand Placement on Brand image. Psychol. Mark., 24(5): 403-420.

Roehm Jr. ML, Roehm HA, Boone DS (2004). Plugs versus Placements: A Comparison of Alternatives for Within-Program Brand Exposure. Psychol. Mark., 21(1): 17-28.

Russell AC (2002). Investigating the Effectiveness of Product Placements in Television Shows: The role of Modality and Plot Connection Congruence on Brand Memory and Attitude. J. Consum. Res., 29(3): 306-318.

Russell AC, Stern BB (2006). Consumers, Characters, and Products: A Balance Model of Sitcom Product Placement Effects. J. Advert., 35(1): 7-21.

Schacter DL (1987). Implicit Memory: History and Current Status. J. Exp. Psychol. Learn. Mem. Cogn., 13(3): 501-518.

Schneider LP, Cornwell TB (2005). Cashing in on Crashes via Brand Placement in Computer Games - The Effects of Experience and Flow on Memory. Int. J. Advert., 24(3): 321-343.

Shapiro SH, Krishnan S (2001). Memory-based Measures for Assessing Advertising Effects: A Comparison of Explicit and Implicit Memory Effects. J. Advert., 30(3): 1-13.

Sunil T, Kohli CS (2011). Can Brand Image Move Upwards after Sideways? A Strategic Approach to Brand Place. Bus. Horiz., 54: 4149.

Tiwsakul R, Hackley C, Szmigin I (2005). Explicit, Non-integrated Product Placement in British Television Programmers. Int. J. Advert., 24(1): 95-111.

Winkler T, Buckner K (2006). Receptiveness of Gamers to Embedded Brand Messages in Advergames: Attitudes towards Product Placement. J. Interact. Advert., 7(1): 37-46.

Yang HL, Wang CS (2008). Product Placement of Computer Games in Cyberspace. Cyberpsychol. Behav., 11(4): 399-404.

Yang M, Roskos-Ewoldsen DR, Dinu L, Arpan LM (2006). The Effectiveness of 'In-game' Advertising. J. Advert., 35(4): 143-152. 


\section{APPENDIX}

Appendix 1. List of items by construct.

\begin{tabular}{|c|c|c|}
\hline Variable & Item & Sources \\
\hline Explicit memory & $\begin{array}{l}\text { EM1: Are there brands or products in prior games that you played? } \\
\text { EM2: If you have seen, what kinds of styles were shown and where did } \\
\text { they appear? }\end{array}$ & $\begin{array}{l}\text { Norris and Colman, } \\
\text { 1993; Shapiro and } \\
\text { Krishnan, } 2001\end{array}$ \\
\hline Implicit memory & $\begin{array}{l}\text { IM1: You must to prepare something for class meeting. Please to check off } \\
\text { the items you would choose. }\end{array}$ & Law and Braun, 2000 \\
\hline \multirow{4}{*}{$\begin{array}{l}\text { Adjective used in } \\
\text { product placement }\end{array}$} & $\begin{array}{l}\text { ADJ1: In the prior game, the product placement in the game is bad/good. } \\
\text { ADJ2: In the prior game, the product placement in the game is dislike/like. } \\
\text { ADJ3: In the prior game, the product placement in the game is } \\
\text { unappealing/ appealing. }\end{array}$ & \multirow{4}{*}{ Bruner, 1998} \\
\hline & $\begin{array}{l}\text { ADJ4: In the prior game, the product placement in the game is unpleasant/ } \\
\text { pleasant. }\end{array}$ & \\
\hline & $\begin{array}{l}\text { ADJ5: In the prior game, the product placement in the game is unfavorable/ } \\
\text { favorable. }\end{array}$ & \\
\hline & $\begin{array}{l}\text { ADJ6: In the prior game, the product placement in the game is } \\
\text { uninteresting/ interesting. }\end{array}$ & \\
\hline \multirow{6}{*}{$\begin{array}{l}\text { Attitude toward } \\
\text { product placement in } \\
\text { video game }\end{array}$} & $\begin{array}{l}\text { AVG1: I don't mind seeing brand name products in games if they are } \\
\text { placed for commercial purposes. }\end{array}$ & \multirow{6}{*}{ Nelson et al. 2004} \\
\hline & $\begin{array}{l}\text { AVG2: I don't mind seeing brand name products in games as long as they } \\
\text { are not unrealistically shown. }\end{array}$ & \\
\hline & $\begin{array}{l}\text { AVG3: I prefer to see real brands in games rather than using fictitious } \\
\text { brands. }\end{array}$ & \\
\hline & $\begin{array}{l}\text { AVG4: Games should use real brands rather than fake/fictitious brands. } \\
\text { AVG5: The presence of brand name products in a game makes it more } \\
\text { realistic. }\end{array}$ & \\
\hline & $\begin{array}{l}\text { AVG6: I generally prefer games that do not have product placements in } \\
\text { them to those that do. }\end{array}$ & \\
\hline & AVG7: I don't mind if brand name products appear in games. & \\
\hline
\end{tabular}

